\title{
Autoridad e imagen DE la EPIDEMia. \\ LA FIEBRE AMARILLA \\ EN LA BARCELONA DEL SIGLO XIX
}

\author{
THE AUTHORITY AND IMAGE OF THE EPIDEMIC. \\ THE Yellow FEVER \\ in the Nineteenth Century Barcelona
}

José Antonio Ortiz García

Universitat de Barcelona

Recibido: 29/03/2017 Evaluado: 18/04/2017 Aprobado: 04/07/2017

RESUMEN: El propósito de este estudio es acercarse al contexto epidémico de Barcelona a lo largo del siglo xix. De forma concreta, la investigación se centra en la fiebre amarilla sufrida en los años 1821 y 1870 . El amplio abanico de referencias propone una mirada interdisciplinar sobre la medicina y las enfermedades en su marco histórico, artístico, social y religioso. ¿Qué reacción tuvieron los poderes municipales?, ¿Qué tipologías artísticas se desarrollaron durante y tras la infección deletérea en Barcelona?

Palabras clave: fiebre amarilla, epidemia, Barcelona, arte, historia de la medicina.

Abstract: The aim of this study is an approach to the epidemic background in Barcelona during the xIx century. Specifically, the research is focus on the yellow fever that was suffered en 1821 and 1870. The large spectrum of references proposes an interdisciplinary point of view about medicine and illnesses in an historic, artistic, social and religious context. How was the official reaction of the municipal powers? What kind of artistic productions were made during and after de epidemic infection in Barcelona?

Keywords: yellow fever, epidemic, Barcelona, Art, Medicine History. 
A nte un brote epidémico aniquilador de la sociedad, las autoridades responden en función de una serie de parámetros que tienen que ver con la especificidad del contexto histórico, político, religioso y médico. Las creaciones artísticas denuncian, muestran, homenajean o ensalzan las actitudes tomadas ante la enfermedad. Sobre estos conceptos oscila este estudio que quiere presentar las producciones artísticas relacionadas con la fiebre amarilla en la ciudad de Barcelona a lo largo del siglo xix, específicamente en los años 1821 y 1870.1

Barcelona como ciudad amurallada medieval se enfrentaba a unas condiciones de higiene y salubridad que desembocan en las nuevas propuestas urbanas en pleno siglo XIX. ${ }^{2}$ Los estudios de Ildefons Cerdà (1815-1876), Teoría general de la urbanización, y de Pere García Fària (1858-1927), Proyecto de saneamiento del subsuelo de Barcelona, son dos muestras de la importancia de la toma de posición ante la realidad opresiva del núcleo histórico de la ciudad. ${ }^{3}$ Los puntos de vista de los autores coinciden en las altas tasas de mortalidad de la población como consecuencia de la estructura del tejido urbano que facilita la propagación de todo tipo de enfermedades.

Si centramos nuestro interés en la propagación de las epidemias, cita Cerdà el número de 6244 fallecidos por fiebre amarilla el año 1821 en su recopilación titulada «Número, clase y duración de las epidemias que han ocurrido en este siglo, y sus efectos espresados por el número de fallecidos en la urbe y suburbios» para la entrada «1 ${ }^{\text {a }}$ en el año 1821. La fiebre amarilla, que duró 111 días en cuyo periodo hubo...». ${ }^{4}$

Estas iniciativas higienistas son reflejo de las necesidades crecientes que atestiguan los datos estadísticos presentados en los proyectos de Cerdà y Fària. Sus referencias a la mortalidad, en caso epidémico especialmente, nos conducen a plantear una mirada global al hecho sanitario barcelonés ante los focos infecciosos. La autoridad médica del Real Colegio de Cirugía se suma a la autoridad política de la Junta Municipal de Sanidad como la figura de

1. Una parte importante de la investigación se ha desarrollado con los expedientes conservados en el Archivo Municipal Contemporáneo de Barcelona (AMCB). Para el año 1821 se conservan los partes de los enfermos (Salut pública: parts malalts febre groga (1, $2 i 3$ ), B 5-H-2) y para el año 1870 los expedientes municipales (Expedients sobre l'epidèmia tifus icterodes de 1870, A-4500, de 1 a 24).

2. Pere Felip Monlau: ¡Abajo las murallas! Memoria acerca de las ventajas que reportaría á Barcelona, y especialmente á su industria, de la demolición de las murallas que circuyen la ciudad, Imp. del Constitucional, Barcelona, 1841. ¡Abajo las murallas! es el título del proyecto del médico, higienista y humanista Pere Felip Monlau (1808-1871) que en el año 1841 proclamaba la necesidad de derribar la muralla medieval que marcaba el perímetro de la ciudad evitando su desarrollo y aumentando la propagación de epidemias. El derribo se ejecutará a partir del año 1854 coincidiendo en época con los proyectos urbanos que modificaran la fisionomía de la ciudad en la segunda mitad del siglo.

3. IldEFONS CERDÀ: Teoría general de la urbanización y aplicación de sus principios y doctrinas á la reforma y ensanche de Barcelona, Imp. Española, 1867; Pere GarCía FÀria: Proyecto de saneamiento del subsuelo de Barcelona, Imp. Henrich y Cía, Barcelona, 1893.

4. CERDÀ: Teoría general de la urbanización..., p. 487. Algunos de los datos estadísticos utilizados por el ingeniero son fruto de su investigación previa sobre las condiciones de la clase obrera que integra a la Teoría general de la urbanización: ILDEFONS CERDÀ: Monografía estadística de la clase obrera, en 1856: espécimen de una estadística funcional de la vida urbana, con aplicación concreta á dicha clase, Imp. Española, 1868. 
referencia en la atención de las epidemias y el control de las fronteras y puerto de la ciudad. ${ }^{5}$ La cronología de la enfermedad en la Barcelona decimonónica nos presenta una oscilación de las infecciones pero un mantenimiento de un patrón regular que diezmaba la población de forma cíclica: 1803, 1821 y 1870 fiebre amarilla; 1834, 1865, 1885 y 1890 cólera, y 1889 gripe.

\section{LAS AUTORIDADES BARCELONESAS ANTE LAS EPIDEMIAS \\ DE FIEBRE AMARILLA}

La autoridad municipal de la enfermedad estaba en manos de la citada Junta Municipal de Sanidad que tiene su origen en las legislaciones del siglo XVIII para el control de la sanidad pública. La Junta Suprema de Sanidad formada por laReal Orden del 18 de septiembre de 1720, en el reinado de Felipe V, fue el primer ejemplo de sistematización y racionalización de la medicina ante la llegada de los miasmas pestilentes. La legislación sanitaria, a través de la impresión de las diversas disposiciones, normas, providencias, cédulas y ordenanzas, intentará responder ante un amplio espectro de asuntos sanitariopreservativos. Esto se materializará en las Juntas Provinciales de Sanidad y las Juntas Municipales de Sanidad con una mirada centrada en los territorios, que serán las nuevas propuestas organizativas para el siglo XIX. La Real Orden de 19 de marzo de 1805, precedida de la Real Resolución de 13 de marzo, exponen el nuevo procedimiento en cuestiones sanitarias: las capitanías generales estaban al cargo, creándose las respectivas Juntas Provinciales de Sanidad de las que los propios capitanes generales serán presidentes.

En este marco legislativo debemos situar el panorama asistencial de las ciudades como Barcelona, foco latente de entrada de las epidemias. Las cuarentenas portuarias y el aislamiento y atención de los enfermos en los lazaretos son dos de las actitudes más habituales a lo largo del siglo xix como freno y control de las situaciones deletéreas. Un ejemplo concreto podría ser el bando sobre la incomunicación del puerto barcelonés como «medida sanitaria dispuesta por la Junta municipal para precaver los estragos de un mal que nos amargaba, no ha podido menos de reducir á un estado verdaderamente infeliz á muchas familias que fundaban en el tráfico y la navegación la esperanza de su subsistencia». ${ }^{6}$

Sin entrar en la geografía concreta de los lazaretos de observación y de infectados en las crisis sanitarias barcelonesas, debemos subrayar la cartografía

5. Josep Lluís Ausin i Hervella: Hospitals provisionals a la Barcelona del segle XIX. Les crisis sanitàries, Publicacions del Seminari Pere Mata, Barcelona, 2002.

6. Al público. La incomunicación del puerto de Barcelona de esta ciudad, Ayuntamiento de Barcelona, Barcelona, 1821. El bando municipal del 16 de agosto de 1821 incluye también la petición de ayuda para la asistencia de los afectados a través de la subscripción en la casa consistorial a cargo de la Comisión permanente de Sanidad. 
de la enfermedad y sus límites urbanos. ${ }^{7}$ Los cordones sanitarios que marcan la frontera entre las zonas infectadas y las no infectadas tienen su razón de ser ante la dualidad médica con la que la ciudad condal y sus autoridades se enfrentan a la enfermedad. Las tesis contagionistas, a medida que avanzan los estudios empíricos de la fiebre amarilla y su propagación por las picadas del mosquito Aedes aegypti, principal vector del virus, perderán posiciones ante el avance de un segundo grupo no contagionista. ${ }^{8}$

Una muestra del debate abierto en la comunidad médica es la reflexión de Ramón Merli i Feixes, médico de la Academia Práctica de Medicina y vocal de la Junta de Sanidad del Principado, en su obra Espurgo de Barcelona..$^{9}$ Ante una ciudad marcada por las fronteras sanitarias, expresa el autor su oposición a las medidas cautelares del año 1821:

La calamidad que acabamos de pasar, ha sido un azote que pudiéndose sofocar en su primera aparición, por descuido se ha desplegado; y cuando por sus terribles efectos se ha aspirado á contenerlo, el pueblo obcecado, no escuchó á aquellos que podían atajarlo; y abandonado á sus erróneos principios permitió que se escampase ó hiciese la devastación que lloran y lloraran innumerables familias por haber perdido el apoyo que las sostenía, quedando los maridos sin mugeres y estas sin esposos, y gran multitud de huérfanos, que andan perdidos sin que nadie los recoja, ni les dé lo necesario para su subsistencia. Por una tal negligencia, y también por una grosería acompañada de una fanática superstición, se creyó en sus principios que este mal no era temible, y que solo por alarmamos se había exagerado, contribuyendo no poco al mantenimiento de estas erróneas ideas la opinión de algunos médicos, que en lugar de sostener las miras del gobierno, publicaron su modo de pensar del todo opuesto á lo que maduramente había declarado. Esta falsa doctrina motivó los sucesos escandalosos de la Barceloneta, y privó á la ciudad de aquellas medidas que en casos idénticos salvaron a los pueblos. ${ }^{10}$

7. Nos remitimos a la bibliografía consultada, especialmente al análisis pormenorizado y la propuesta de planimetrías de Ausin i Hervella: Hospitals provisionals a la Barcelona del segle XIX...

8. El médico Carlos Juan Finlay y Barrés (1833-1915) fue quien estudió la fiebre amarilla, y por su análisis llegó a la conclusión de que la transmisión de la enfermedad se realizaba por un agente intermediario, siendo capaz de identificar en 1881 al mosquito Aedes aegypti como el agente transmisor. Uno de los documentos más interesantes sobre el debate abierto en Barcelona es el Manifiesto acerca del origen y propagación de la calentura que ha reinado en Barcelona en el año 1821, Imprenta de Albán y Compañía, Madrid, 1822. En esta segunda edición se añaden nuevas ideas para marcar la posición científica de un grupo de médicos ante las ideas generales que reinaban en Barcelona y en su junta sanitaria. La crítica a las medidas tomadas son evidentes en fragmentos como el siguiente: «El único y más seguro medio que adoptó el gobierno, que fue la emigración (...) contra un contagio imaginario, han sido un insulto á la humanidad y una prueba la más auténtica del atraso é ignorancia en que ha submergido á los pueblos la rutina sanitaria (...) Que ha sido epidémica. Que no ha sido contagiosa, Que las medidas adoptadas por el gobierno han sido precarias, del todo inútiles y aun perjudiciales, si se esceptúa la de la emigración», p. 11.

9. Ramon Merlí i Feixes: Espurgo de Barcelona, Imprenta de la Viuda de D. Antonio Brusi e Hijos, Barcelona, 1821.

10. Merlí i Feixes: Espurgo de Barcelona, p. 5. La referencia del texto a «los sucesos escandalosos de la Barceloneta» nos presenta en un documento de la época, la indignación ante la incomunicación del barrio portuario barcelonés de la Barceloneta, considerándolo el foco principal de la enfermedad. 
Otras publicaciones de los miembros del Real Colegio de Cirugía y del Real Colegio de Farmacia nos permiten acercarnos documentalmente a las propuestas de curación que en la época se practicaban. Textos de farmacopea y tratados médicos han sido motivo de investigación en las últimas décadas por parte de la historia de la medicina. ${ }^{11}$ Ejemplos del siglo XVIII como la Relación de las epidemias de calenturas pútridas y malignas que en estos últimos años se han padecido en el Principado de Cataluña y principalmente de la que descubrió el año pasado de 1783 en la ciudad de Lérida, Llano de Urgél: con el método de curar semejantes enfermedades, se pueden poner en contraste con los publicados en el siglo XIX a raíz de las plagas manteniendo algunas ideas preconcebidas aplicadas por las autoridades municipales. ${ }^{12}$ Ante la fiebre amarilla en el siglo XIX son el vinagre y la quina los remedios que suelen estar asociados a los tratamientos, siguiendo el método del Dr. Tadeo Lafuente. ${ }^{13}$

La ciencia médica de los tratamientos y de las disposiciones cuarentenarias entra en relación con el imaginario taumatúrgico de las autoridades religiosas. Más allá de la asistencia física a los cuerpos afectados, la Iglesia desarrolla su programa litúrgico y devocional ante los casos infecciosos. Destaca el Te Deum como celebración de acción de gracias con que la sociedad barcelonesa pone punto final a la epidemia. Además, a lo largo de la evolución de la patología se realizan una serie de actividades pastorales para la remisión de la plaga y la sanación de los afectados. Para el año 1821 disponemos del documento conservado en el Archivo de la Catedral de Barcelona (ACB) como parte del Llibre d'exemplars de la sagristia II (1758-1851). En el folio 111 bajo la entrada «Pregarias per Epidemia» se hace un resumen de las procesiones y las disposiciones religiosas para los días 18, 20 y 22 de septiembre de 1821, en pleno brote pestilente, para subsanar la situación de la ciudad. ${ }^{14}$ Destaca en el texto la

11. Núria SAUCh CRUZ: «La febre groga de 1821 a Tortosa: origen, propagació, prevenció i mètode de curació de la malaltia», Recerca, 8, 2004, pp. 339-344; MARÍA DolORES GASPAR I GARCía y Josep Maria Suñé I ARbussà: «Notes d'interès medicofarmacèutic sobre l'epidèmia de febre groga del 1821 a Barcelona», Gimbernat, XX, 1993, pp. 179-186.

12. Josep MASDEVAll I Terrades: Relación de las epidemias de calenturas pútridas y malignas que en estos últimos años se han padecido en el Principado de Cataluña y principalmente de la que descubrió el año pasado de 1783 en la ciudad de Lérida, Llano de Urgél: con el método de curar semejantes enfermedades, Imprenta Real, Madrid, 1786. Especifica el autor en el capítulo V del tratado, pp. 68-69, «El método específico y seguro para conseguir una curación feliz de estas enfermedades epidémicas, y de qualesquiera otras calenturas pútridas y maligna (...) el Médico sea llamado á visita algún enfermo acometido por alguna de estas especies de calenturas, le prescribirá mi mixtura antimonial que se compone del modo siguiente: aquae viperinae, aquae benedictae, Rulandi (termino clariori) vini emetici, cremoris tartari pulverati \& fiat mixtura ad usum».

13. GaSPAR y SuNÉ: «Notes d'interès...», p. 180. Esta metodología es también referenciada en el manuscrito estudiado en el siguiente artículo: MARÍA DOLORES GASPAR: «La epidemia de fiebre amarilla que asoló Barcelona en 1821, a través del contenido del manuscrito 156 de la Biblioteca Universitaria de Barcelona», Gimbernat, XVIII, 1992, pp. 65-72.

14. ACB: Llibre d'exemplars de la sagristia II (1758-1851), fol. 111. Inicia así la cota documental: «Trobantse la Ciutat de Barcelona en lo Any 1821 atacada de una forta Epidemia, el Excelentíssim Ajuntament resolgué fer pregarias per la Ciutat, imediatament parà un Ofici al Molt Ilustríssim Capítol per resoldrer lo que se hauria de fer y los Ilustres Senyors feren los Comicionats per resoldrer lo que se hauria de fer, y fou lo seguent: Fer tres días de rogativa y foren en los días 18, 20 y 22 del mes de setembre de dit Any (...)». 
implicación de la totalidad de la ciudad, ayuntamiento y capítulo catedralicio para aunar fuerzas y llevar a cabo la liturgia protectora. El urbanismo de la ciudad es campo de batalla ante la enfermedad pero también es escenario de las procesiones que entre las diferentes parroquias se realizan en estos tres días.

En el 1870 incluso los bandos municipales evocan la intervención de Dios para la remisión de le epidemia. Así se expresaba la Junta Municipal de Sanidad de Barcelona con motivo del punto y final de la cuarentena barcelonesa:

\begin{abstract}
¡Dios ha escuchado nuestras fervientes súplicas! Extinguiéndose la calamidad que ha pesado sobre nosotros, tan solo quedan como su natural consecuencia algunos aislados casos, que no constituyen ya epidemia, postreras convulsiones de la enfermedad agonizante. Al llanto del dolor deben suceder las lágrimas de reconocimiento, y por ello congregadas mañana vuestras Autoridades y esta Junta Municipal de Sanidad en el Santo Templo, elevarán sus preces al Altísimo en acción de gracias: que no ha muerto, no, en los catalanes corazones la ardiente fe heredada de nuestros antepasados (...). ${ }^{15}$
\end{abstract}

ENTRE LA INFORMACIÓN, LA CARICATURA Y EL HOMENAJE. El IMAGINARIO VISUAL DE LA ENFERMEDAD

El foco principal de este estudio, una vez presentado el contexto histórico, médico y religioso, es el análisis de las demostraciones artísticas con motivo de la enfermedad. La fuente principal es la prensa de la época, encargada de informar de la situación. Los artículos acompañados de las imágenes nos muestran las cartografías de los campamentos, las vistas de la ciudad y de su puerto. Junto a estas creaciones descriptivas se halla otro grupo que tiende a caricaturizar o presentar la patología bajo una perspectiva irónica y fuertemente crítica ante las soluciones adoptadas por la autoridad. Un tercer grupo sería el formado por las creaciones fruto del homenaje a los fallecidos y a los que activamente participaron en la erradicación de la enfermedad. Esta clasificación es la que proponemos como aproximación al imaginario visual de la fiebre amarilla o tifus icterodes.

El primer grupo consta de los dibujos, grabados y fotograbados que aportan a las narraciones escritas una visibilidad de la epidemia. La gran mayoría de las imágenes localizadas presentan la topografía de los campamentos de evacuación y del puerto de Barcelona, foco principal de entrada y de contaminación.

Emigración de los habitantes de la Barceloneta con motivo de la fiebre amarilla es una de las creaciones de Ramon Padró Pedret (1838-1915) y Tomás Carlos Capuz (1834-1899) para La Ilustración Española y Americana. ${ }^{16}$ Se narran los hechos de la siguiente manera:

15. ¡Dios ha escuchado nuestras fervientes súplicas!, Junta Municipal de Sanidad, Barcelona, 1870.

16. La Ilustración Española y Americana, 05/10/1870, p. 348. El Archivo Histórico de la Ciudad de Barcelona (AHCB) conserva un recorte de la imagen, AHCB 4545. 


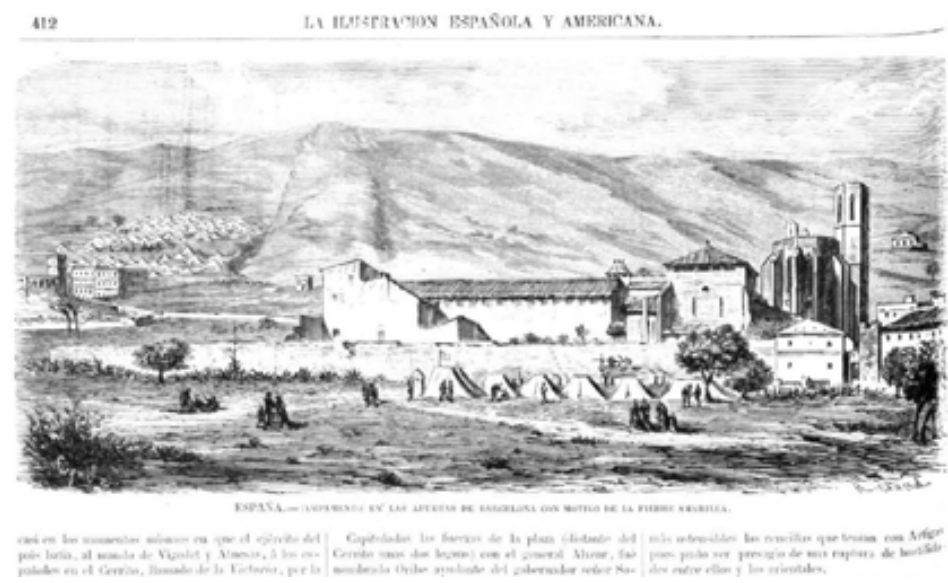

Fig. 1. La Ilustración española y americana, 15/11/1870, p. 412, detalle

Los periódicos han referido las tristes causas que han dado lugar al desarrollo de la fiebre amarilla en Barcelona. La Barceloneta, ó sea el arrabal de la marina, ha sido desde el primer momento cruelmente castigado por tan terrible azote. (...) Los habitantes de la Barceloneta abandonan sus hogares para refugiarse en la ciudad. La escena es desoladora, y constituye, por decirlo así, el principio de las calamidades que pesan sobre la capital del Principado (...). ${ }^{17}$

Campamento con motivo de la fiebre amarilla es el título que se otorga a la imagen publicada el 15 de noviembre de 1870 en La Ilustración Española y Americana (fig. 1). Presenta este número el grabado de Capuz de la siguiente forma:

Nuestros lectores saben que al poco tiempo de declararse la fiebre amarilla en la capital de Cataluña, la autoridad militar dispuso, con el objeto de evitar que se cebase en las tropas tan terrible enfermedad, la salida de algunas fuerzas de la guarnición. El grabado que publicamos en la pág. 412 representa el campamento formado para albergar las tropas en los alrededores de la capital. ${ }^{18}$

El grabado del campamento militar, con el monasterio de Pedralbes como marco arquitectónico, pertenece al dibujo Campamento en Pedralbes con motivo de la fiebre amarilla de 1870 conservado en el Archivo Histórico de la Ciudad de Barcelona (AHCB). ${ }^{19}$

17. La Ilustración Española y Americana, 05/10/1870, p. 343.

18. La Ilustración Española y Americana, 15/11/1870, p. 407.

19. AHCB 01123. La inscripción nos remite al artista Lluís Rigalt (1814-1894) tal y como consta en el catálogo del Museo de Historia de Barcelona (MHCB) que hace referencia a la misma pieza, MHCB 11099. 


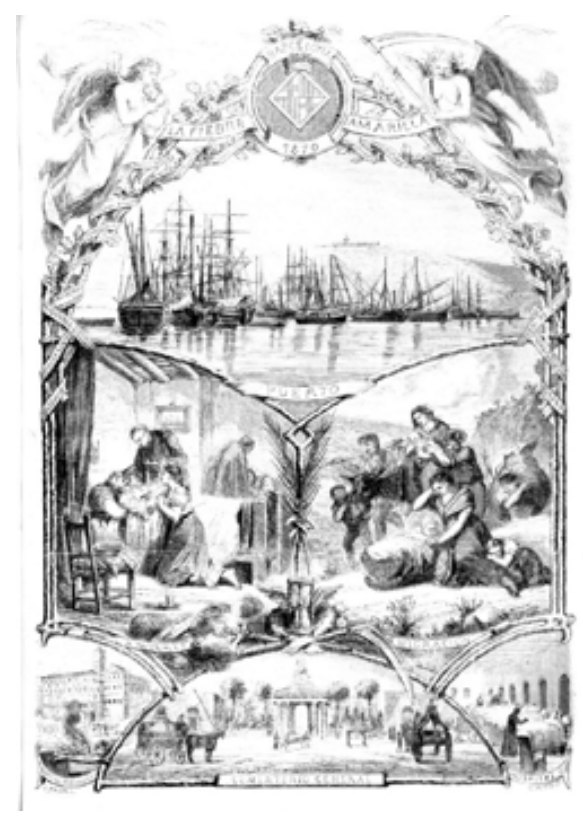

Fig. 2. La Ilustración española y americana, 25/11/1870, p. 430, detalle

Diez días después, en la misma publicación, se presenta la imagen más conocida de la fiebre amarilla junto a su artículo explicativo (fig. 2) ${ }^{20}$ Lo visual y lo textual se complementan. La descripción de la enfermedad, las actitudes de los políticos y de los fabricantes, la evacuación de los ciudadanos y la apertura del sistema asistencial hospitalario, dan un enfoque épico a como las autoridades han manejado la epidemia de 1870. En el grabado de Padró y Capuz, filacterias nos aportan las leyendas de las diferentes secciones del mismo a página entera: «PUERTO», «LA MUERTE», «EMIGRACIÓN», «HOSPITAL PROVISIONAL», «CEMENTERIO GENERAL» $\mathrm{y}$ «HOSPITAL». Otras inscripciones nos remiten a los personajes y entidades que formaron parte de la lucha contra la epidemia. El ángel protector y el ángel con la guadaña dominan la parte superior y se ciernen sobre el puerto de la ciudad que deja paso a la muerte y a la emigración. La asistencia a los enfermos en sus lechos de muerte se opone a las familias que huyen hacia el interior alejándose de la franja marítima. Enla ciudad, la asistencia en los hospitales se completa con la que ofrecen los provisionales. Aun así, no pueden hacer frente a las elevadas tasas de mortalidad que conducen inexorablemente al cementerio. Abre este su entrada principal a los féretros y carruajes en la parte inferior del grabado. 
La Esquella de la Torratxa en 1901 recupera un grabado anterior. En la sección «Barcelona. Recorts del sigle XIX» presenta una visión del campamento militar en la montaña de Montjuïc con motivo de la epidemia del 1821. 1821. Campamento sanitario de la Constitución, establecido en la falda Norte de Montjuïch, durante la epidemia de la fiebre amarilla. Comprendía 400 barracas capaces para 100 personas cada una es el texto que figura en la leyenda que se complementa con la referencia a un grabado anterior publicado por la imprenta Brusi. El AHCB conserva el recorte del fotograbado y así mismo un grabado y el dibujo de este sobre papel vegetal con las indicaciones numéricas y textuales de cada una de las partes de la imagen. ${ }^{21}$ La atención a los campamentos militares es una de las muestras que nos han legado en los fondos patrimoniales dada la atención prestada en la prensa a esta tipología de obras.

El AHCB conserva también en sus fondos dos grabados extraídos de la prensa, 1821. Escenas de la epidemia (De un romanso) y La fiebre amarilla (1821); junto a dos dibujos, Puerto de Barcelona durante la epidemia de 1870 y Calle de Vermell durante la fiebre amarilla de $1870 .{ }^{22}$ El primero de este elenco corresponde a la ilustración original del Diálogo entre Feliu y Jaumet abitants de Barcelona: refereix cada qual lo que li succehi durant la epidemia en la ciutat lo any 1821, un romance editado en 1822 que aúna imagen y literatura sobre la plaga. ${ }^{23}$ La xilografía muestra la crudeza de la patología, con los ataúdes y la presencia de la muerte en plena ciudad ante los militares y religiosos. El texto con su carácter directo y con la difusión popular de esta tipología impresa nos acerca con vivacidad a las calles de la ciudad:

(...) Totas las portas tancadas,/ningú, ningú treballant,/resonant de quant en quant/las fúnebres martelladas/las caixas amontonadas,/y si rodas se sentían,/ ja nostres cors se oprimían,/pues sols se veyan anarhi,/ó nostre Amo ab lo vicari,/ó los metjes que assisitían (..... ${ }^{24}$

El segundo grupo de obras son las que presentan una respuesta crítica por parte de la prensa. La Campana de Gracia o Lo Ponton son dos ejemplos satíricos ante la enfermedad. En el año 1870 podemos recorrer páginas y páginas que comentan los estragos de la epidemia y que muestran con ironía su desarrollo. El 2 de octubre de 1870 La Campana de Gracia en portada presenta un dibujo titulado Entre la espasa y la febre groga como reflexión ante el contexto bélico y médico en el que se encuentra la ciudad (fig. 3). Bar-

21. AHCB 11975; AHCB 4670; AHCB 2044.

22. AHCB 22133; AHCB 4413; AHCB 1167; AHCB 1166. Las dos últimas referencias formaban parte de la colección de dibujos de Raimon Casellas (1855-1910) que pasaron a la Junta de Museos de Barcelona y posteriormente a instituciones patrimoniales como la del AHCB.

23. Diálogo entre Feliu y Jaumet abitants de Barcelona: refereix cada qual lo que li succehi durant la epidemia en la ciutat lo any 1821, Imprenta de Joseph Torner, Barcelona, 1822.

24. Una traducción sería la siguiente: «Todas las puertas cerradas,/ nadie, nadie trabajando,/ resonando de tanto en cuanto/ los fúnebres martillazos/ las cajas amontonadas,/ y si ruedas se sentían,/ ya nuestros corazones se oprimían,/ pues solo se veían ir/ o nuestro Amo con el vicario,/ o los médicos que asistían». 


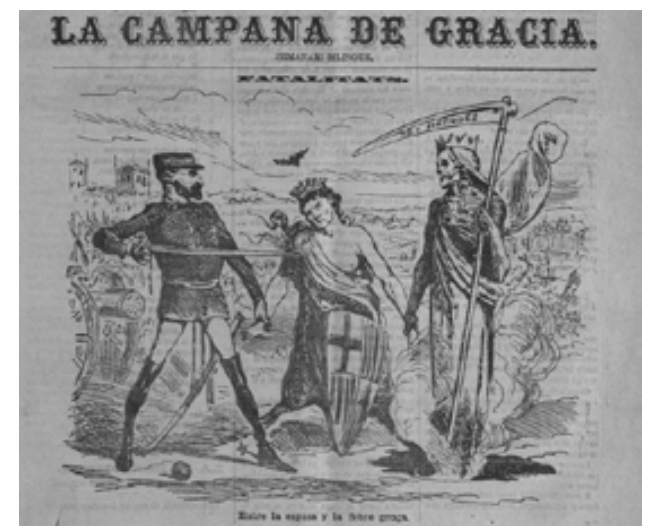

Fig. 3. La Campana de Gracia, 02/10/1870, p. 1, detalle

celona, como alegoría femenina con el escudo de la ciudad, se debate entre los cañones y la guadaña de la muerte. En la cuarta página del semanario se muestran los Datos de la fiebre amarilla recogiendo la mortalidad acaecida en Cádiz (1800 y 1804) y Barcelona (1821) y deseando ante el nuevo crecimiento de la población «que hoy la misma enfermedad no causará tantos estragos. ¡Ojalá no nos equivoquemos!». ${ }^{25} \mathrm{El}$ artículo precisa, además, las medidas tomadas, como la cuarentena y fumigación para los que salen de la ciudad y la habilitación de la plaza de toros de Valencia para controlar a los pasajeros llegados a la estación, procedentes de Barcelona.

El 9 de octubre la portada de La Campana de Gracia es una sátira sobre las medidas adoptadas por los ciudadanos, siguiendo la lectura de un artículo de la época firmado por Damas Calvet sobre el papel del sistema de alcantarillado ante el combate pestilente. ${ }^{26}$ Cestas de mimbre protegen las caras de los personajes ilustrados que huyen de la ciudad (fig. 4). ${ }^{27}$ Huir de la ciudad era el recurso de las clases sociales altas. El bienestar de los que se alejan se pone en duda en el número del 23 de octubre que se abre con un interior rural en el que duermen diversas personas en jergones, el niño desnudo llora y sobre la silla reposa una chistera y la crinolina de un vestido femenino (fig. 5). ${ }^{28}$

25. La Campana de Gracia, 02/10/1870, p. 4. Días antes, el mismo semanario bilingüe publicaba una crónica de la enfermedad en 1821 con una relación diaria de los atacados y muertos en los meses de septiembre y agosto. Se cita la necesidad informativa ante la plaga: «Creemos de sumo interés transcribir en las columnas de nuestro periódico la relación del estado sanitario del distrito municipal de Barcelona durante la epidemia de la fiebre amarilla en el año 1821» (La Campana de Gracia, 25/09/1870, p. 3).

26. Se hace referencia a Damas Calvet i de Budallès (1836-1891) ingeniero, poeta y dramaturgo.

27. La Campana de Gracia, 09/10/1870, p. 1.

28. La Campana de Gracia, 23/10/1870, p. 1. 


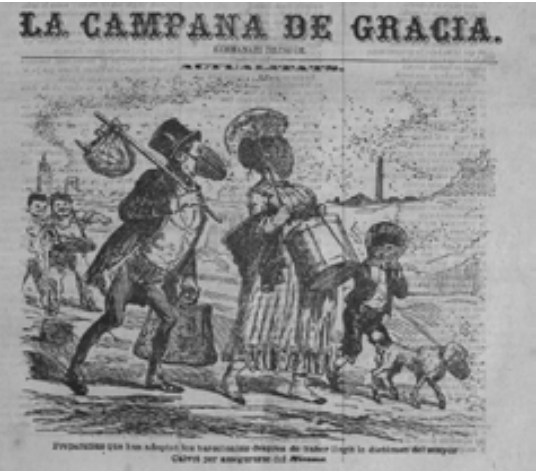

Fig. 4. La Campana de Gracia, 09/10/1870, p. 1, detalle
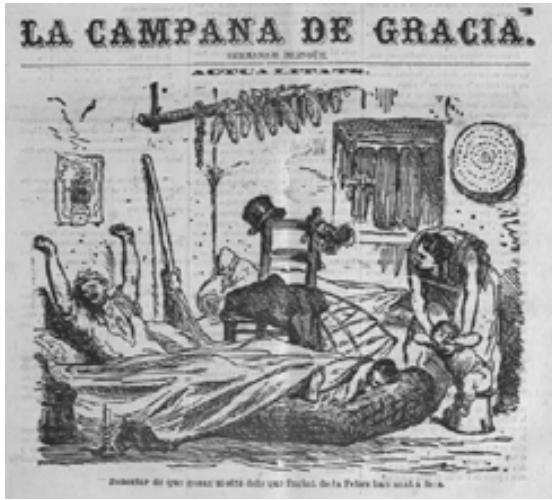

Fig.5. La Campana de Gracia, 23/10/1870, p. 1, detalle

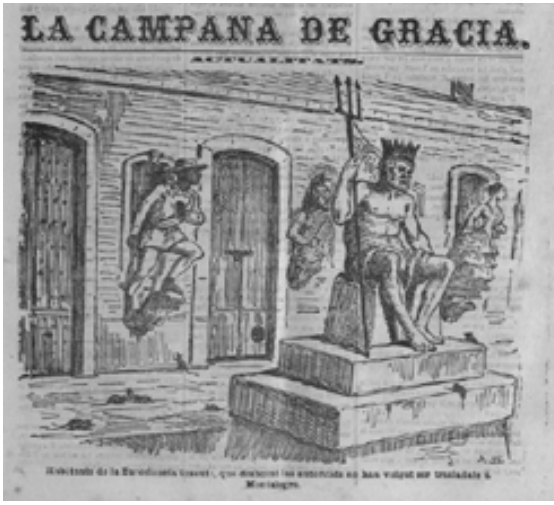

Fig. 6. La Campana de Gracia, 30/10/1870, p. 1, detalle 


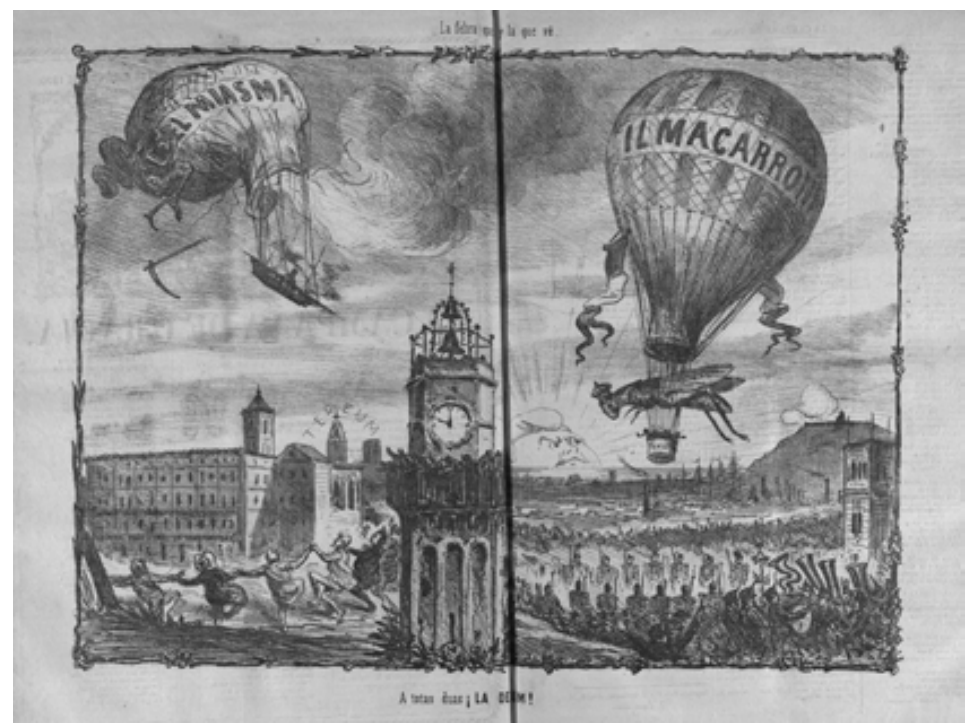

Fig. 7. La Campana de Gracia, 27/11/1870, pp. 2 y 3, detalle

La realidad urbana es uno de los factores centrales para el despliegue satírico de La Campana de Gracia. A medida que pasan las semanas la ciudad se vacía. El barrio de la Barceloneta se desaloja, siendo conducidos sus habitantes al entorno controlado de Montalegre. Las esculturas y los mascarones de proa que decoraban los edificios parecen habitantes que desoyen a las autoridades y se quedan en las calles vacías pero plagadas de ratas (fig. 6). Así lo cita la leyenda de la ilustración: «Habitants de la Barceloneta tussuts, que deshoint las autoritats no han volgut ser trasladats á Montalegre». ${ }^{29}$

El 26 de noviembre tuvo lugar el Te Deum o himno litúrgico de acción de gracias que puso fin a la epidemia. Al día siguiente, 27 de noviembre, La Campana de Gracia a doble página presenta una vista de Barcelona sobrevolada por dos globos aerostáticos, el de la fiebre amarilla que se desinfla, El miasma, y la llegada de Il Macarroni como nuevo contexto político tildado de plaga por comparación (fig. 7). ${ }^{30}$

29. La Campana de Gracia, 30/10/1870, p. 1. El texto en catalán dice: «Habitantes de la Barceloneta tozudos, que desoyendo a las autoridades no han querido ser trasladados a Montalegre». El 17 de septiembre de 1870 la población de la Barceloneta fue evacuada al monasterio de Montalegre en la montaña de la Conreria a las afueras del municipio de Tiana (Espediente relatiu a l'Epidèmia de Tifus Icterodes (Febre Groga) Que Ha Sofert Barcelona Durant l'Any 1870. Instal.lació d'Una Colònia Sanitària Al Convent de Montalegre, Archivo Municipal Contemporáneo de Barcelona, número de expediente A-4500.15, fol. 3).

30. La Campana de Gracia, 27/11/1870, p. 2-3. En el contexto histórico del Sexenio Democrático o Sexenio Revolucionario (1868-1874) se hace referencia en la caricatura al reinado de Amadeo I (1871-1873) denominado por su origen italiano «Il Macarroni». 
Más allá de las ediciones contemporáneas a la epidemia, la memoria del tifus icterodes queda presente en la sociedad, y a lo largo de la última parte del siglo XIX se encuentran referencias a la enfermedad en imágenes que la recuerdan o usada en jeroglíficos. La Esquella de la Torratxa propone un jeroglífico el día 6 de diciembre de 1879 en el que se puede leer «Nadal-Corpus-Cólera morbo-Febre groga». La solución aportada el 13 de diciembre nos desvela que «Las festas per alguns son pestas». ${ }^{31}$ Esta misma publicación el 8 de junio de 1894 ilustra sus páginas con un dibujo de una familia sufriendo fiebre amarilla implorando la clemencia divina. ${ }^{32}$ En el imaginario colectivo quedan grabadas las epidemias y sus estragos.

El tercer grupo de producciones que queremos comentar engloba los homenajes oficiales a la epidemia. Destaca un conjunto de obras de producción francesa, tanto grabados como pinturas y composiciones literarias. La comisión de médicos franceses en Barcelona durante la epidemia de 1821 produjo una dilatada producción artística que culmina con el trato heroico hacía los médicos que como André Mazet (1793-1821) fallecieron contagiados. El nuevo heroísmo de la ciencia que representan estos personajes ha sido motivo de estudio en publicaciones como La peste à Barcelone. En marge de l'histoire politique et littéraire de la France sous la Restauration de Léon François Hoffmann que recopila en sus láminas los grabados de esta temática. ${ }^{33} \mathrm{El} \mathrm{AHCB}$ conserva en sus fondos uno de ellos, Barcelone en 1821, representando a tres médicos de la comisión en una sala que se abre a un espacio de tratamiento de los enfermos. La escultura de Esculapio y el busto de Mazet completan la estancia. ${ }^{34}$ El estudio de Hoffman se centra en las composiciones literarias derivadas, que nos permiten observar la difusión del tema de la enfermedad en Francia, también a través de las medallas conmemorativas.

Conmemorar es la intención de las obras promovidas por el Ayuntamiento de Barcelona en recuerdo de los fallecidos por la enfermedad. Podemos comentar dos producciones pensadas para un contexto funerario, el cenotafio del cementerio de Poblenou (Barcelona) y la lápida del denominado cementerio del cólera o de los Apestados (Tiana). En el primer caso tenemos un proyecto ideado en el 1823 y reformado en 1895 (fig. 8). Tradicionalmente se atribuye el concepto original a Antonio Ginesi (1791-1824) y la reformulación del mismo a Leandre Albareda (1852-1912). ${ }^{35}$ Autores como Fabre y Huertas

31. La Esquella de la Torratxa, 06/12/1879, p. 4; La Esquella de la Torratxa, 13/12/1879, p. 3.

32. La Esquella de la Torratxa, 08/06/1894, p. 356

33. LÉon François Hoffman, La peste à Barcelone. En marge de l'histoire politique et littéraire de la France sous la Restauration, Princeton University y Presses Universitaires de France, New Jersey y Paris, 1964.

34. AHCB 4544. Otro grabado sería el titulado Mazet dans une rue de Barcelone, citando el ejemplar conservado en Londres en la Wellcome Library, no. 5450i, disponible en el catálogo en línea de la institución: $<$ http://catalogue.wellcomelibrary.org/record=b1168842> (consultado 14/03/2017). La pintura La mort de Mazet, de Henri Auguste César Serrur (1794-1865) del Musée de Cambrai sería otra de lascreaciones derivadas de la exaltación de los médicos galos en Barcelona.

35. El cementerio del Este o de Poblenou es una iniciativa episcopal del obispo Josep Climent i Avinent (1706-1781) del 1775. Durante la ocupación napoleónica este espacio fue diezmado por el conflicto y por ello en 1816 se inició la reconstrucción llevada a cabo por Antonio Ginesi con un estilo neogótico y neoe- 


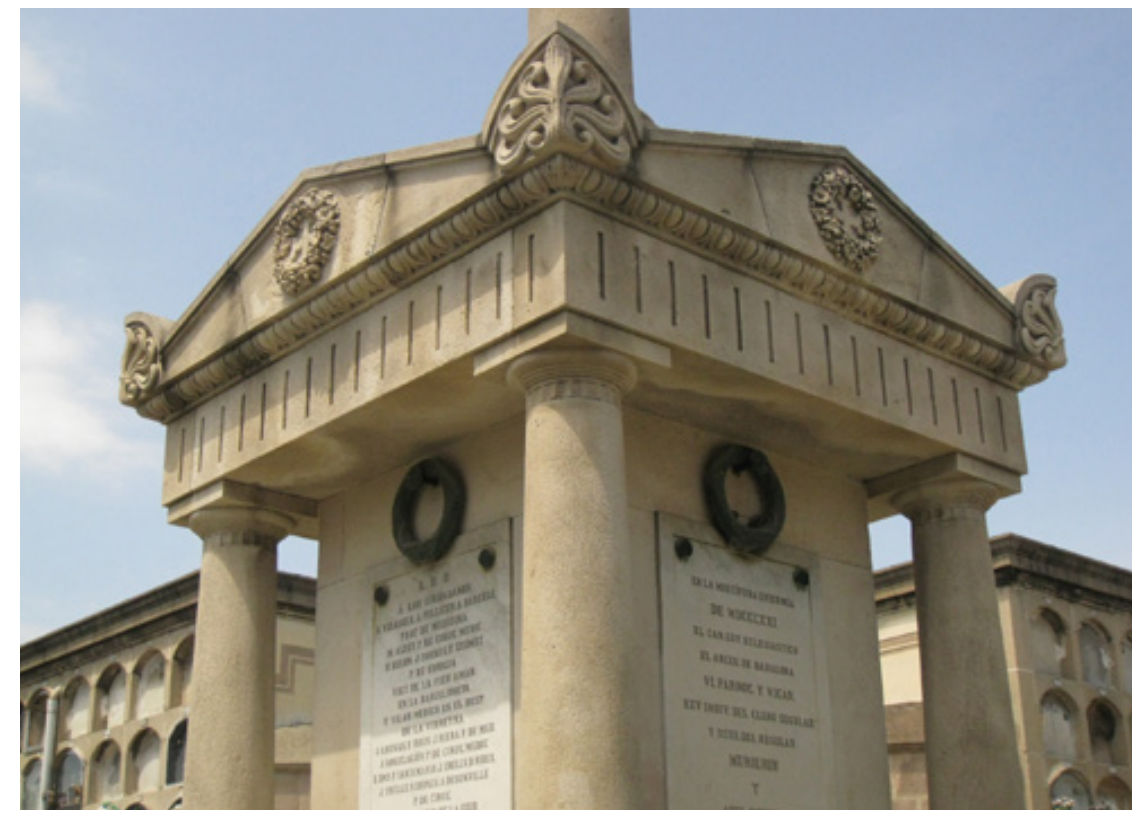

Fig. 8. A las víctimas de la epidemia de fiebre amarilla de 1821. Cementerio de Poblenou, Barcelona, detalle. Créditos de la imagen: Catálogo Art Públic de Barcelona (Creative Commons Attribution-Share Alike 3.0 Spain)

lo sitúan en 1852 como proyecto municipal para ser instalado ante la fachada principal de la casa consistorial de Barcelona en la calle Ciutat, obra de Francesc Daniel Molina (1812-1867), realizado finalmente en el camposanto. ${ }^{36} \mathrm{El}$ monumento cívico A las víctimas de la fiebre amarilla de 1821, elaborado en mármol blanco, presenta un estilo clásico rematado por una columna con una cruz en lo alto. En los cuatro lados del cenotafio se encuentran placas conmemorativas, una en recuerdo de las víctimas, otra en memoria de los concejales del Ayuntamiento muertos por la misma causa, y dos dedicadas a los colectivos que más se involucraron en la lucha contra la epidemia, los médicos y los eclesiásticos. ${ }^{37} \mathrm{La}$ reminiscencia de los traspasados en la epidemia se convierte

gipcio que sigue las fórmulas internacionales para la distribución de los espacios internos. La fosa común de las víctimas de la fiebre amarilla estaría situada en el recién inaugurado cementerio, marcada por un monumento atribuido al arquitecto del conjunto.

36. Así se especifica en el catálogo municipal de escultura pública del Ayuntamiento de Barcelona, en la versión impresa y la versión digital que citamos:

<http://w10.bcn.cat/APPS/gmocataleg_monum/CambiaIdiomaAc.do?idioma=ca\&pagina=welcome> (consultado 16/03/2017).

37. Las inscripciones correspondientes a cada placa son las siguientes: «En el año 1821 apareció en esta ciudad de Barcelona una enfermedad cruel, calificada de fiebre amarilla, que arrebató la existencia á muchos millares de habitantes. Sus restos se depositaron en este Campo Santo. Orad por sus almas»; «A.D.O. A los ciudadanos Vilaseca, Pellicer y Barceló, prof. de Medicina; M. Altés, prof. de Cirug. Médico; D. Delom, F. Torres, F. Guimet, P. de Cirugía víct. de la fieb. Amar. en la Barceloneta; V. Vilar, médico en el Hosp. de la 
en el foco central del urbanismo del cementerio, el cruce de las vías principales que distribuyen los diferentes sectores funerarios del departamento primero.

Cierta relación guarda el espacio de memoria creado en el que fue el cementerio de los enfermos de fiebre amarilla evacuados a la colonia del monasterio de Montalegre en el municipio de Tiana. Actualmente el recinto es de titularidad pública y es un espacio inmerso en el entorno natural de la Conreria bajo el nombre equívoco de cementerio del cólera o de los apestados. Destaca la losa sepulcral en piedra con la inscripción «Colonia de Montalegre. El Ayuntamiento de Barcelona a las víctimas de la fiebre amarilla 1870». Instalada en 1871, mantiene esta lauda funeraria la historia local de esta población en una crisis sanitaria. En los archivos del AHCB hemos localizado el proyecto original realizado por el arquitecto municipal de Barcelona y firmado el 5 de diciembre de $1870 .{ }^{38}$ Josep Artigas y Ramoneda (1839-1912) rodea el escudo de la ciudad condal con la inscripción anteriormente mencionada y completa los espacios con relojes de arena alados y cráneos con sus huesos cruzados.

Como apunte final en nuestro estudio, los tratados médicos son también una fuente visual para estudiar el impacto de la fiebre amarilla en las artes. Observations sur la fièvre jaune, faites à Cadix, en 1819 de los doctores Étienne Pariset y André Mazet es la obra paradigmática del género. ${ }^{39}$ Ilustran la investigación médica desarrollada en Cádiz durante el brote de 1819 con la evolución de los síntomas en un paciente en cuatro planchas. Grabado tras grabado empeora la situación del joven culminando en sudores producidos por la fiebre, el vómito negro que caracteriza la enfermedad y la derivación amarilla de la tez del muchacho (fig. 9 y fig. 10). ${ }^{40}$

Virreina; J. Arenas, F. Ros, J. Riera, P. de Med. E. Oms, P. Santamaría, J. Trulls, B. Ribas, J. Trulls, R. Depaus, A. Desunville P. de Cirug. dent. los mur. de la Ciud. en el año de 1821 Barcelona traslada á la posteridad este triste monumento de gratitud»; «En la mortífera epidemia de MDCCCXXI el Can. Gob. Eclesiástico, el Arced. de Badalona, VI Párroc. y Vicar, XXV indiv. del clero secular y XCIII del regular murieron y aquí reposan víctimas y ejemplo de caridad y constancia religiosa»; «Barcelona en demostración de gratitud dedica esta inscripción á la memoria de los Alcaldes constitucionales D. Cayetano de Dou y el Marqués de Alfarrás, y de los regidores D. José Rovira, D. Juan Barnola y D. Juan Gil y Juliá que, fieles al juramento de cumplir debidamente el encargo que les confirieron sus conciudadanos, permanecieron firmes en la Ciudad dirigiendo los negocios públicos y aliviando á la humanidad infeliz hasta caer víctimas de la enfermedad cruel que la afligió en el año 1821».

38. AHCB 3258. Se puede cotejar este documento con las referencias históricas a la instalación de la colonia en el monasterio de Montalegre del Archivo Municipal Contemporáneo de Barcelona (AMCB) que conserva el expediente titulado Relatiu a l'Epidèmia de Tifus Icterodes (Febre Groga) Que Ha Sofert Barcelona Durant l'Any 1870. Instal-lació d'Una Colònia Sanitària Al Convent de Montalegre (Número de expediente A-4500.15). Del folio 307 al 320 del citado documento se listan 447 personas procedentes de la Barceloneta en el «Padron general de los albergados en el asilo del Monasterio de Montalegre» a las que se unen los «69 corrigendos y 13 reclusos de la casa Municipal de Corrección de Barcelona». Completa esta información la entrada «Colonia de Montalegre 22 septiembre-10 diciembre 1870. Defunciones» y «Relacion alfabético de los fallecidos en la Colonia de Montalegre», ambas sin foliar sobre las muertes acaecidas.

39. Étienne Pariset, y André Mazet, Observations sur la fièvre jaune, faites à Cadix, en 1819, Audot, París, 1820.

40. Podemos citar el ejemplar de la Bibliothèque National de France (BNF) con la cota FOL-TD54-74 o el de la Wellcome Library en su catálogo en línea: <http://catalogue.wellcomelibrary.org/record=b1120677> (consultado 14/03/2017). 


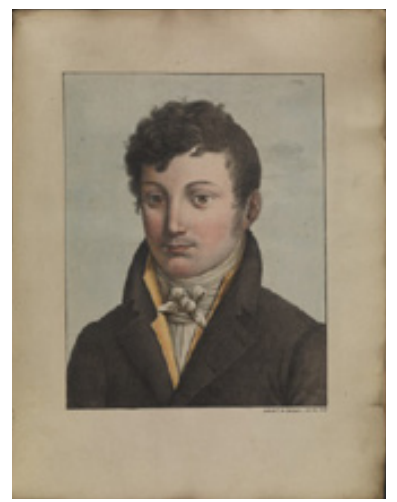

Fig. 9. Étienne Pariset y André Mazet: Observations sur la fièvre jaune, faites à Cadix, en 1819, Audot, París, 1820. Créditos de la imagen: Wellcome Library, Londres (Creative Commons Attribution only licence CC BY 4.0.)

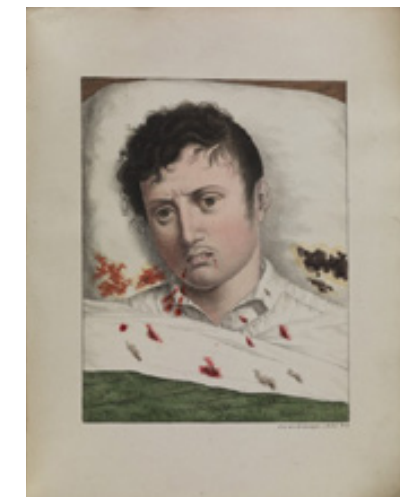

Fig. 10. Étienne Pariset y André Mazet: Observations sur la fièvre jaune, faites à Cadix, en 1819, Audot, París, 1820. Créditos de la imagen: Wellcome Library, Londres (Creative Commons Attribution only licence CC BY 4.0.)

Memoria históricocientífica sobre la epidemia de fiebre amarilla sufrida en Barcelona en 1870 es uno de los numerosos tratados publicados con motivo de la epidemia y contagio. ${ }^{41}$ Destacamos este por la inclusión al final del volumen de dos planchas litografiadas con las observaciones hechas en el microscopio de la sangre, el agua y el cieno del puerto barcelonés para su estudio. Resulta muy interesante la intención médica de plasmar con imágenes los estudios que

41. Antonio Mendoza, Memoria histórico-cientifica sobre la epidemia de fiebre amarilla sufrida en Barcelona en 1870, Establecimiento Tipográfico de Jaume Jepús, Barcelona, 1872. 
se estaban realizando. No es tanto presentar la sintomatología externa como en el tratado francés comentado, sino ahondar en la microbiología de la plaga e ilustrar los avances aportados por la Real Academia de Medicina y Cirugía de Barcelona.

Este estudio ha sido una aproximación a la realidad de la plaga del tifus icterodes en un contexto histórico-artístico. Barcelona fue sitiada por otras enfermedades que nos permitiría desarrollar un trabajo equiparable ante las reacciones dadas a otras epidemias. La metodología seguida ha sido el vaciado de los fondos de hemerotecas, como una fuente relevante de investigación, cotejada con otras tipologías documentales de diferentes instituciones patrimoniales y archivos. Paralelamente se han indagado los espacios de conservación de la memoria de los fallecidos en los cementerios. Gracias a los estudios ya publicados sobre historia, medicina y farmacia, hemos podido aportar una mirada transversal que quería reflejar el impacto social de la plaga como detonante de la creación artística. Las respuestas culturales son una expresión de las sociedades ante el dilema de la patología y las intervenciones llevadas a cabo por las autoridades competentes. La documentación de archivo permite además personificar a las víctimas: sus nombres y apellidos, sus domicilios, profesiones y edades, entre otros datos, han llegado a nosotros aportándonos una mirada íntima a los contagiados y contagiadas de la fiebre amarilla en la Barcelona del siglo XIX.

\section{BiBLIOGRAFÍA}

Al público. La incomunicación del Puerto de Barcelona de esta ciudad, Ayuntamiento de Barcelona, Barcelona, 1821.

Ausin i Hervella, Josep Lluís: Hospitals provisionals a la Barcelona del segle XIX. Les crisis sanitàries, Publicacions del Seminari Pere Mata, Barcelona, 2002.

CERDÀ, ILdefons: Monografía estadística de la clase obrera, en 1856: espécimen de una estadística funcional de la vida urbana, con aplicación concreta á dicha clase, Imp. Española, 1868.

- Teoría general de la urbanización y aplicación de sus principios y doctrinas á la reforma y ensanche de Barcelona, Imp. Española, 1867.

Diálogo entre Feliu y Jaumet abitants de Barcelona: refereix cada qual lo que li succehi durant la epidemia en la ciutat lo any 1821, Imprenta de Joseph Torner, Barcelona, 1822.

García FÀria, Pere: Proyecto de saneamiento del subsuelo de Barcelona, Imp. Henrich y Cía, Barcelona, 1893.

Gaspar i García, María Dolores: «La epidemia de fiebre amarilla que asoló Barcelona en 1821, a través del contenido del manuscrito 156 de la Biblioteca Universitaria de Barcelona», Gimbernat, XVIII, 1992, pp. 65-72.

Gaspar i García, María Dolores, y Josep Maria Suñé i Arbussà: «Notes d'interès medicofarmacèutic sobre l'epidèmia de febre groga del 1821 a Barcelona», Gimbernat, XX, 1993, p. 179-186. 
HoffMAN, LÉON FrançOIS: La peste à Barcelone. En marge de l'histoire politique et littéraire de la France sous la Restauration, Princeton University y Presses Universitaires de France, New Jersey y París, 1964.

Manifiesto acerca del origen y propagación de la calentura que ha reinado en Barcelona en el año 1821, Imprenta de Albán y Compañía, Madrid, 1822.

MasdeVall i Terrades, Josep: Relación de las epidemias de calenturas pútridas y malignas que en estos últimos años se han padecido en el Principado de Cataluña y principalmente de la que descubrió el año pasado de 1783 en la ciudad de Lérida, Llano de Urgél: con el método de curar semejantes enfermedades, Imprenta Real, Madrid, 1786.

Mendoza, Antonio: Memoria histórico-científica sobre la epidemia de fiebre amarilla sufrida en Barcelona en 1870, Establecimiento Tipográfico de Jaume Jepús, Barcelona, 1872.

Merlí i Feixes, Ramon: Espurgo de Barcelona, Imprenta de la Viuda de D. Antonio Brusi e Hijos, Barcelona, 1821.

Monlau, Pere Felip: ¡Abajo las murallas! Memoria acerca de las ventajas que reportaría á Barcelona, y especialmente á su industria, de la demolición de las murallas que circuyen la ciudad, Imp. del Constitucional, Barcelona, 1841.

Pariset, Étienne, y André Mazet: Observations sur la fièvre jaune, faites à Cadix, en 1819, Audot, Paríis, 1820.

NúRIA SAUCH CRUZ: «La febre groga de 1821 a Tortosa: origen, propagació, prevenció i mètode de curació de la malaltia», Recerca, 8, 2004, pp. 339-344. 